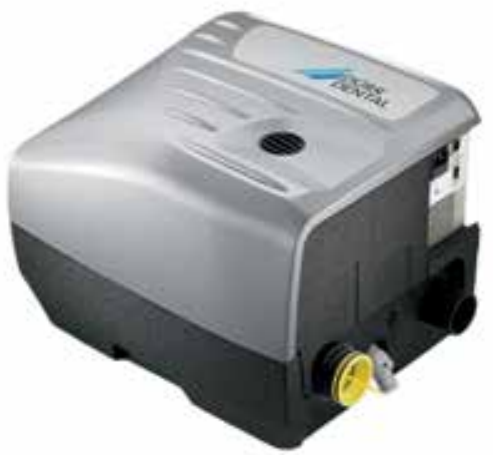

\title{
Neuer Standard in der Praxisversorgung
}

Sauganlagen von Dürr Dental stehen seit Jahrzehnten für Robustheit, zuverlässige Leistung und Langlebigkeit. Die neueste Generation dieser Systeme arbeitet dank innovativer Technologie extrem sparsam und weist exzellente Leistungsmerkmale auf. In den neuen Tyscor VS 2 Sauganlagen kommt erstmals die robuste und leistungsfähige Radialtechnik zum Einsatz, die vor allem aus industriellen Anwendungen bekannt ist. Sie zeichnet sich durch maximale Ausfallsicherheit aus und ermöglicht gegenüber der herkömmlichen Seitenkanalverdichtung eine deutlich platzsparendere Bauweise. Ein Aggregat für 2 Behandlungsplätze ist damit sehr viel kompakter und wiegt weniger als die Hälfte des vergleichbaren Vorgängersystems. Trotzdem vereint es alle notwendigen Module - Saugmotor, elektronische Steuerung und die Separierstufe. Mit gerade einmal $11 \mathrm{~kg}$ Gewicht und den Abmessungen eines handelsüblichen Mikrowellengeräts für die Küche, ist die Generation Tyscor äußerst kompakt. Ausgezeichnete Werte zeigt das Gerät auch bei der Effizienz: Die Systeme kommen bei gleicher Leistung mit bedeutend weniger Energie aus als ihre konventionellen Vorgänger. Die Software Tyscor Pulse zeigt alle relevanten Statusdaten und Service-Intervalle der Sauganlage auf dem Monitor an und sorgt damit für vollständige Übersicht zu jedem Zeitpunkt. Regelmäßige Sichtkontrollen werden damit überflüssig. Bei Bedarf unterstützt die Software sogar Ferndiagnose durch einen Servicetechniker, der sich direkt in das System einloggen kann. Das Risiko von Ausfallzeiten wird dadurch so minimal wie möglich gehalten. Saugleistung und Nachlaufzeit können über das Praxisnetzwerk vom PC aus eingestellt werden.

\section{Nach einer Pressemitteilung der \\ DÜRR DENTAL AG, Bietigheim-Bissingen}

4)

